\title{
ANALISIS KONTEN PERSEPSI ATLET WANITA MUSLIM TERHADAP ATURAN BERPAKAIAN OLAHRAGA VOLI PASIR DI INDONESIA
}

\author{
Yulia Prayanti', Sulhaini ${ }^{2}$, Akhmad Saufi ${ }^{3}$ \\ 1Program Studi Magister Manajemen, Fakultas Ekonomi dan Bisnis Unram \\ E-mail: yuliaprayanti123@gmail.com \\ 2Fakultas Ekonomi dan Bisnis, Universitas Mataram \\ E-mail: sulhaini@unram.ac.id \\ ${ }^{3}$ Fakultas Ekonomi dan Bisnis, Universitas Mataram \\ E-mail: akh.saufi72@gmail.com
}

\begin{tabular}{|c|c|}
\hline ARTICLE INFO & ABSTRACT \\
\hline 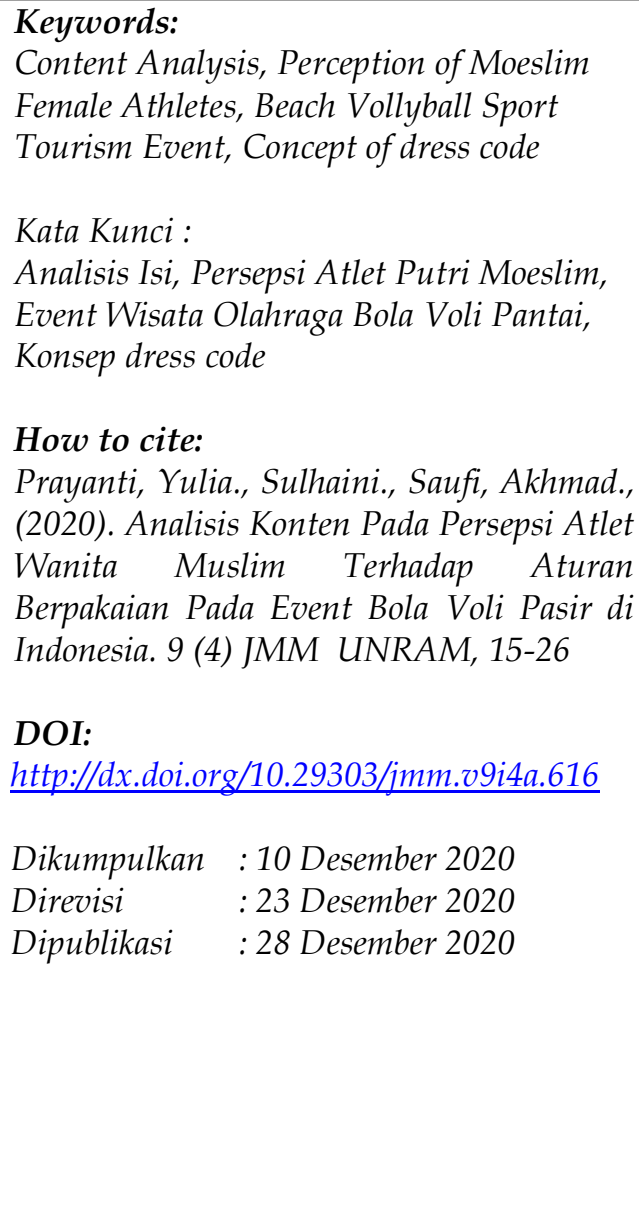 & $\begin{array}{l}\text { This study aims to determine how to conduct an analysis } \\
\text { in a phenomenon to find out the perception of Moslem } \\
\text { female athletes of the dress code at beach volleyball } \\
\text { events in Indonesia with a content analysis approach. } \\
\text { Data collection was carried out through observation, } \\
\text { interviews and documentation on Moslem female } \\
\text { athletes in Indonesia. The results of this study found } \\
\text { three main categories from } 13 \text { themes which are } \\
\text { interrelated dimensions, they are authenticity and } \\
\text { professionalism orientation, moderate orientation and } \\
\text { athlete's achievement. These findings indicate that the } \\
\text { relationship between perceptions, attitudes and the use } \\
\text { of dress codes for Moslem female athletes in beach } \\
\text { volleyball events. } \\
\text { Penelitian ini bertujuan untuk mengetahui bagaimana } \\
\text { melakukan analisis dalam sebuah fenomena yakni untuk } \\
\text { menemukan persepsi atlet wanita muslim terhadap } \\
\text { aturan berpakaian pada event bola voli pasir di } \\
\text { Indonesia dengan pendekatan analisis konten. } \\
\text { Pengumpulan data dilakukan melalui observasi, } \\
\text { wawancara dan dokumentasi pada atlet wanita muslim. } \\
\text { Hasil penelitian ini ditemukan tiga kategori utama dari } \\
\text { 13 tema yang menjadi dimensi yang saling berkaitan } \\
\text { yaitu Orientasi otentisitas dan profesionalisme, } \\
\text { Orientasi moderat dan prestasi atlet Orientasi nilai } \\
\text { agama dan budaya. Hasil temuan ini menunjukkan } \\
\text { keterkaitan persepsi, sikap dan penerapan aturan } \\
\text { berpakaian untuk atlet wania muslim pada event bola } \\
\text { voli pasir }\end{array}$ \\
\hline & $\begin{array}{l}\text { Copyright (C) 2020. Yulia Prayanti, Sulhaini, } \\
\text { Akhmad Saufi. All rights reserved. }\end{array}$ \\
\hline
\end{tabular}




\section{PENDAHULUAN}

Olahraga bola voli pasir menjadi salah satu strategi dalam pengembangan pariwisata olahraga di Indonesia (Utomo, 2018). Salah satu upaya yang dilakukan adalah melalui event sport tourism dalam bentuk kejuaraan olahraga baik nasional maupun internasional (purnamasari, 2011). Indonesia yang memiliki potensi kekayaan sumber daya alam seperti pantai, telah dioptimalkan menjadi bentuk event sport tourism untuk cabang olahraga bola voli pasir (Rivani, 2018). Hal ini ditandai dengan beberapa daerah di Indonesia menjadi tuan rumah penyelenggaraan event olahraga bola voli pasir ajang internasional singleevent dan mulitievent

Olahraga bola voli pasir juga menjadi salah satu cabang olahraga prestasi di Indonesia khususnya di NTB. Atlet - atlet bola voli pasir NTB sering menyumbangkan medali pada event nasional maupun internasional (Lubis, Satrianingsih, dan Irmansyah, 2017; PBVSI NTB, 2019) Tidak hanya sebagai ajang prestasi dan olahraga wisata, olahraga bola voli pasir tapi juga dianggap sebagai salah satu tontonan olahraga terseksi di dunia. Atlet - atlet wanita yang hanya menggunakan bikini menjadi daya tarik bagi cabang olahraga ini (Gillespie, 2017).

Federation Internasional Vollyball (FIVB) yang mengeluarkan aturan resmi aturan berpakaian pertandingan untuk peserta wanita yaitu penggunaan two piece bikini yang disesuaikan dengan lokasi dan kondisi suhu pertandingan yaitu di lakukan di daerah pantai, sehingga tidak mempengaruhi kecepatan, dan kebebasan begerak di atas pasir (FIVB, 2019) Tidak sedikit pihak yang menolak diberlakukannya aturan tersebut. Weaving dalam Buns of Gold, Silver and Bronze (2012) mengatakan bahwa ada masalah dengan aturan seragam dan presentasi voli pasir. Aturan yang diberlakukan tidak memungkinkan seorang wanita Muslim, untuk bersaing pada event tersebut. Wirdati, (2006) dan Waljee, (2008) menjabarkan aturan tersebut menjadi diskriminasi bagi atlet wanita muslim dalam olahraga.

Untuk itu karena desakan dari beberapa pihak FIVB memperbarui peraturan pada 2012 untuk memungkinkan pemain mengenakan pakaian lebih tertutup dalam upaya untuk menghormati kepercayaan budaya yang berbeda di seluruh dunia. Di beberapa negara Islam, khususnya di Indonesia perubahan peraturan tersebut sudah disosialisasikan dan diaplikasikan sehingga memberikan peluang atlet voli pasir wanita Muslim untuk berpartisipasi dalam event olahraga bola voli pasir. Atlet wanita tidak harus mengenakan bikini, namun banyak atlet lebih suka memakai two piece bikini karena dianggap menjadi ciri khas dan identitas cabang olahraga bola voli pasir (FIVB.com, 2012).

Berkaitan dengan hal tersebut persepsi atlet wanita Muslim di Indonesia dalam melihat aturan berpakaian pada event bola voli pasir memiliki peran yang signifikan terhadap perilaku terhadap aturan tersebut (Pelana, 2013). Persepsi dari sudut pandang perilaku individu adalah proses kegiatan memilih, menerima dan mengatur dan menginterpretasikan informasi yang ada untuk mendapat gambaran yang berarti terhadap obyek tertentu (Kusmaningrum dan Dian, 2009; Kreitner dan Kinici,2007; Saputra dan Samuel, 2013). Dalam hal ini beberapa atlet wanita Muslim memilih untuk tetap mengikuti aturan yang dikeluarkan induk organisasi olahraga tersebut. Beberapa diantaranya memilih untuk tetap mengikuti aturan berpakaian sesuai syariat Islam dengan mengenakan jilbab, lengan panjang, atau celana olahraga longgar yang merupakan indentitas sebagi Muslimah.

Qureshi dan Ghouri (2011); dan Marwat, Zia-ul-Islam, Waseem, (2014) tentang persepsi dan pengalaman wanita Muslim di Minnesota tentang seragam olahraga, penelitian ini menunjukan bahwa. Banyak wanita Muslim yang memiliki minat tinggi terhadap olahraga, namun sangat sedikit yang dapat menyalurkannya hingga mengikuti event yang Internasional. 
Penelitian ini juga menegaskan bahwa dibutuhkan upaya lebih lanjut agar minat wanita Muslim dalam berolahraga dapat tersalurkan dengan baik tanpa melanggar aturan dan syariat Islam yang berlaku.

Artikel ini membahas tentang penelitian kualitatif dalam konteks persepsi atlet wanita muslim terhadap aturan berpakaian pada event bola volii pasir di Indonesia. Penelitian ini dilakukan dengan mengikuti prinsip kualitatif dan metode analisis konten Penelitian ini bertujuan untuk mengetahui bagaimana melakukan analisis dalam sebuah fenomena yakni menemukan persepsi atlet wanita muslim terhadap aturan berpakaian pada event bola volii pasir di Indonesia dengan pendekatan analisis konten dan mengembangkan hasil-hasil dari penelitian sebelumnya sesuai dengan tujuan penggunaan analisis konten.

\section{KAJIAN PUSTAKA}

\subsection{Anaisis Konten}

Analisis konten merupakan jenis studi kualitatif yang didefinisikan sebagai sekumpulan prosedur untuk mempelajari isi teks tertulis atau ditranskrip yang memungkinkan peneliti untuk memasukkan sejumlah besar informasi tekstual dan secara sistematis mengidentifikasi sifat-sifatnya seperti frekuensi kata kunci yang paling sering digunakan (Klenke, 2008). Menurut Krippendorff (2012), analisis konten memungkinkan peneliti membuat kesimpulan yang dapat direplikasi dan valid dari data ke konteksnya. Data tekstual dapat dalam bentuk verbal, cetak, atau elektronik dan dapat diperoleh dari tanggapan naratif, pertanyaan survei terbuka, wawancara, kelompok fokus, observasi, atau media cetak seperti artikel, buku, atau manual (Kondracki \& Wellman, 2002).

Tujuan menggunakan analisis konten sebagai metode penelitian adalah untuk memberikan wawasan baru dan meningkatkan pemahaman tentang fenomena tertentu, dan untuk mendapatkan deskripsi fenomena yang lebih luas dan lebih ringkas, serta untuk mendeskripsikan dan mengukur suatu fenomena (Moldavska \& Welo, 2017). Analisis konten sebagai metode mencakup strategi penelitian kuantitatif dan kualitatif. Analisis kuantitatif memberikan hasil berupa frekuensi, biasanya menjawab pertanyaan 'berapa'. Analisis kualitatif menyajikan data dalam bentuk kategori, memungkinkan interpretasi teks (Bengtsson, 2016). Analisis konten kualitatif mencoba mengatasi kekurangan analisis kuantitatif seperti memberikan jawaban tentang bagaimana kategori diturunkan dengan menerapkan pendekatan sistematis yang dipandu teori untuk analisis teks.

\subsection{Persepsi}

Persepsi merupakan suatu proses kegiatan memilih, menerima dan mengatur dan menginterpretasikan informasi yang ada untuk mendapat gambaran yang berarti terhadap obyek tertentu (Kusmaningrum dan Dian, 2009; Kreitner dan Kinici,2007; Saputra dan Samuel, 2013). Menurut Thoha (2014) persepsi pada hakekatnya adalah proses kognitif yang dialami oleh setiap orang didalam memahami informasi tentang lingkungannya, baik lewat penglihatan, pendengaran, penghayatan, perasaan dan penciuman. Menurut Joseph (2013) persepsi berpengaruh secara parsial terhadap Keputusan individu.

Keyakinan Agama adalah salah satu dari banyak faktor yang mempengaruhi persepsi dan perilaku individu (Kotler dan Keller dalam Fikri dan Pane, 2019). Pengaruhnya tergantung pada komitmen individu untuk keyakinan, kegiatan dan ritual keagamaan (Wilson dan Liu, 2011). Sehingga keyakinan agama pada wanita muslim dapat mempengaruhi persepsi wanita muslim dalam menetukan sikap dan perilaku mereka terhadap apa yang mereka lihat dan rasakan dalam berpartisipasi dalam olahraga. (Ahmad, 
2017; Hamzeh dan Oliver, 2012; Alam et al., 2011). Untuk itu, agama dapat mempengaruhi persepsi dan perilaku sesorang (Battour, Hakimian, Ismail, dan Bogan, 2018; Pandjaitan, 2018).

\subsection{Atlet Wanita Muslim}

Atlet adalah individu yang terlibat dalam aktivitas olahraga dengan memiliki prestasi di bidang olahraga (Satiadarma ,2012). Dalam Undang-Undang Republik Indonesia nomor 3 tahun 2005 tentang sistem keolahragaan nasional, olahragawan adalah pengolahraga yang mengikuti pelatihan secara teratur dan kejuaraan dengan penuh dedikasi untuk mencapai prestasi. Atlet berperan dalam suatu aktivitas dibidang keolahragaan dan bakat, keterampilan, maupun motivasi sangat dibutuhkan pada cabang olahraga tersebut untuk mencapai suatu prestasi yang setinggi-tingginya dan dikumpulkan dalam satu program pelatihan yang lebih khusus dan intensif sesuai dengan cabang olahraga masing-masing. Atlet juga yang memiliki keunikan dan memiliki bakat tersendiri, pola perilaku, dan keperibadian yang baik serta memiliki latar belakang kehidupan yang mempengaruhi secara spesifik pada dirinya (Rusdianto 2014).

Bagi beberapa wanita muslim keputusan menjadi menjadi atlet merupakan sebuah pilihan. Sebagai seorang atlet yang memiliki kepribadian yang baik maka akan menjunjung tinggi peraturan-peraturan olahraga di mana ia bermain dan bertanding. Namun terkadang aturan yang dikeluarkan oleh induk organisasi menjadi hambatan dan tantangan bagi beberapa atlet muslim. Hal ini tergantung dari persepsi atlet dalam melaksanakan aturan tersebut.

\subsection{Konsep Aturan Berpakaian}

Dalam Islam aturan berpakaian merupakan bentuk ketakwaan dalam pemenuhan ketentuan-ketentuan agama. Berbusana sesuai syariat Islam merupakan pengamalan akhlak terhadap diri sendiri, menghargai dan menghormati harkat dan martabat dirinya sendiri sebagai makhluk yang mulia. Bagi wanita muslim menutup aurat adalah suatu hal yang wajib, Banyak wanita Muslim mengadopsi praktik mengenakan jilbab sesuai dengan komitmen mereka terhadap kepatuhan beragama dan praktik kesopanan (Amara, 2008). Namun tidak semua wanita Muslim mengenakan jilbab atau pakaian Islami, berbagai situati politik, ekonomi, dan sosial telah terbukti memengaruhi pilihan wanita Muslim dalam berpakaian (Amara, 2008; Esposito dan Mogahed, 2007).

Banyak peraturan olahraga secara tidak sengaja melarang atlet wanita Muslim mengenakan jilbab (Erickson, 2017). Dalam event olahraga, Federasi olahraga memiliki aturan ketat tentang seragam olahraga yang menentukan apa yang bisa dan tidak bisa dipakai atlet, dari olahraga profesional hingga olahraga sekolah. Namun aturan-aturan ini biasanya ditulis dengan mempertimbangkan populasi mayoritas, tidak mempertimbangkan beragam kebutuhan populasi minoritas, seperti wanita Muslim yang mempraktikkan pakaian tertutup. Hal ini menyebabkan banyak masalah ketika wanita Muslim akan berpartisipasi dalam olahraga, tetapi kebutuhannya akan pakaian tertutup tidak dipenuhi oleh aturan berpakaian yang disetujui. Salah satunya pada cabang olahraga bola voli pasir.

Dalam Event olahraga voli pasir federation Internasional Vollyball (FIVB) yang mengeluarkan aturan resmi untuk aturan berpakaian bertanding untuk peserta wanita yaitu penggunaan two piece bikini. Menurut FIVB aturan berpakaian yang dikeluarkan untuk dipakai pada saat pertandingan disesuaikan dengan lokasi dan kondisi suhu pertandingan yaitu di lakukan di daerah pantai, selain itu juga mempengaruhi kecepatan, dan kebebasan begerak di atas pasir. (FIVB, 2009). Namun saat ini aturan seragam voli pasir resmi FIVB 
untuk semua event voli pantai sudah disesuaikan dengan keyakinan masing - masing atlet dan kebijakan di masing - masing negara.

\subsection{Penelitian Terdahulu}

Penelitian yang dilakukan oleh Pattison, J. A. (2013) mengemukakan bahwa wanita menggunakan pakaian dan penampilan untuk memahami identitas olahraga dan identitas gender ketika wanita bermain bola voli di perguruan tinggi dan bahwa mereka saat ini menggunakan pakaian dan penampilan dalam kehidupan sehari-hari sebagai cara untuk memahami posisi subjek mereka. Atlet voli perguruan tinggi wanita mengkonseptualisasikan cara mereka memahami harapan sosial dan budaya dengan menggunakan pakaian dan praktik penampilan serta tubuh mereka sebagai media interpretasi.

Selanjutnya Qureshi dan Ghouri (2011); dan Marwat, Zia-ul-Islam, Waseem, (2014) juga menunjukkan hasil yang sama namun penelitian ini lebih difokuskan terhadap aturan berpakaian di event internasional. Banyak wanita Muslim yang memiliki minat tinggi terhadap olahraga, namun sangat sedikit yang dapat menyalurkannya hingga mengikuti event yang lebih tinggi. Penelitian ini juga menegaskan bahwa dibutuhkan upaya lebih lanjut agar minat wanita Muslim dalam berolahraga dapat tersalurkan dengan baik tanpa melanggar aturan dan syariat Islam yang berlaku. Benn dan Dagkas (2013), mengemukakan kendala yang dihadapi wanita Muslim dikarenakan piagam olimpiade yang berkomitmen untuk kesamaan hak asasi manusia dalam partisipasi olahraga dan bebas dari diskriminasi berdasarkan gender serta agama, ternyata memiliki peraturan pakaian olahraga yang masih bertolak belakang dengan komitmen tersebut hal ini terbukti beberapa induk organisasi olahraga yang menjadi anggota Internasional Olympic Committee (IOC), mengeluarkan aturan berpakaian yang menjadi kendala wanita Muslim untuk bersikap sopan dalam menutupi tubuh dalam berolahraga.

\section{METODE PENELITIAN}

\section{1. $\quad$ Metode Penelitian}

Jenis penelitian yang digunakan dalam penelitian ini adalah penelitian kualitatif dengan pendekatan analisis konten. Pendekatan pada analisis konten dapat dibedakan menjadi dua yaitu analisis induktif dan deduktif (Moretti et al., 2011). Penelitian ini menggunakan pendekatan induktif yang merupakan proses perpindahan dari yang spesifik ke umum, berarti bahwa contoh-contoh pidato tertentu diamati dan kemudian digabungkan menjadi pernyataan yang lebih besar. Pendekatan deduktif, di sisi lain, bergerak dari yang umum ke yang spesifik (Burns \& Grove, 2005). Analisis konten deduktif digunakan untuk menguji ulang data yang ada dalam konteks baru, menguji kategori, konsep, model, atau hipotesis. Ini biasanya didasarkan pada pekerjaan sebelumnya seperti teori, model, peta pikiran, dan tinjauan literatur (Hsieh \& Shannon, 2005). Salah satu tantangan analisis konten adalah kurangnya resep atau standar umum untuk pelaksanaannya. Oleh karena itu, kualitas analisis konten telah dibahas secara luas oleh para peneliti. Dalam kasus analisis konten, istilah seperti validitas, reliabilitas, dan kepercayaan telah digunakan untuk menangani kualitas penelitian (Elo et al., 2014). 


\subsection{Perencanaan}

Perencanaan dimulai dengan menentukan informan yang sesuai dengan rumusan masalah sehingga temuan di lapangan bisa menjadi instrument dalam pengembangan penelitian.Penelitian ini menggunakan teknik purposive sampling dalam proses penentuan informan. Purposive sampling sangat sesuai dengan penelitian kualitatif karena peneliti tertarik pada informan yang memiliki pengetahuan terbaik tentang topik penelitian. Informasi dalam penelitian ini merupakan penggiat olahraga voli pasir di Indonesia, Latar belakang informan meliputi Pengurus PBVSI NTB, Pelatih olahraga Voli Pasir, Atlet wanita muslim voli Atlet wanita muslim olahraga voli pasir di Indoensia, atlet wanita muslim olahraga lainnya di Indonesia. Untuk mendapatkan peserta ditentukan dengan menggunakan metode purposive. Peserta yang terlibat meliputi dari semua penggiat olahraga voli pasir dan atlet wanita muslim dengan fokus utama atlet wanita muslim voli pasir pada yang sudah pernah mengikuti event bola voli pasir tingkat Internasional.

Tabel 1 Informan Penelitian

\begin{tabular}{|c|c|}
\hline Nama Informan & Keterangan \\
\hline - Surya Bahari & Pengurus PBVSI NTB \\
\hline - Sukemi & Pengurus PBVSI NTB \\
\hline - Agus Salim & Pelatih Voli Pasir INA \\
\hline - Ni putu timi yudani rahayu & Pelatih Voli Pasir Pelatda NTB \\
\hline - Heni Rahayu & Pelatih Voli Pasir PelatdaNTB \\
\hline - $\quad$ Dhita Juliana & Atlet Voli Pasir INA \\
\hline - Putu Dini Jasita Utami & Atlet Voli Pasir INA \\
\hline - Desi Ratna sari & Atlet Voli Pasir INA \\
\hline - $\quad$ Allisa muthaharah & Atlet Voli Pasir INA \\
\hline - Devi Melinda Novita & Atlet Voli Pasir INA \\
\hline - Saqwa Amelia Permata Putri & Atlet Voli Pasir INA \\
\hline - $\quad$ Atika Baweany & Atlet Voli Pasir INA \\
\hline - Arum Purari Eka & Atlet Voli Pasir INA \\
\hline - $\quad$ Nanda Gili & Atlet Voli Pasir Pelatda DKI \\
\hline - Arista suci agiandini & Atlet Voli Pasir PPLP NTB \\
\hline - $\quad$ Alda permatasari & Atlet Voli Pasir PPLP NTB \\
\hline - $\quad$ Astrid Ocktavia Bahari & Atlet Voli Pasir Pelatda NTB \\
\hline - Vita Bahari & Atlet Voli Pasir Pelatda NTB \\
\hline - Sari Hartati & Atlet Voli Pasir Lampung \\
\hline - $\quad$ Baiq Friska Milanonita Erdiani & Atlet Voli indoor Lombok Tengah \\
\hline - Wafa Nafisah Amwayandya & Atlet Voli indoor Yogyakarta \\
\hline - Indah Purwaningsih & Atlet Voli indoor Kalimantan barat \\
\hline - $\quad$ Mita Pertiwi & Atlet Voli indoor Yogyakarta \\
\hline - $\quad$ Indri Agustianti & Atlet Voli indoor Yogyakarta \\
\hline - Anggi Kana & Atlet Voli indoor Lombok Tengah \\
\hline - Dwi Putri Kisnasari & Atlet Kempo INA \\
\hline - Mira Intan Baiduri & Atlet Kempo NTB \\
\hline - Griselda Nadya Billy & Atlet Kempo Bali \\
\hline - $\quad$ Sayyida Nafisa Zarkasi & Atlet Kempo DIY \\
\hline - vini febriani hasan & Atlet Kempo Lampung \\
\hline - $\quad$ septianingrum dewi & Atlet Kempo Jatim \\
\hline - Tara Devilia Hidayati & Atlet Kempo Lobar \\
\hline - Wahida Ayuningtias & Atlet Kempo Lotim \\
\hline - $\quad$ Adelita Scania Wulandari & Atlet Kempo Yogyakarta \\
\hline
\end{tabular}




\begin{tabular}{lll}
\hline - & Dwi Aryanti & Atlet Kempo DKI \&Pelatih gymnastic \\
\hline - & Yanni HS & Atlet Kempo Sumatra Barat \\
\hline - & Nurzakina Asyari & Atlet Pencak silat Jawa timur \\
\hline - & Dewi Lantari & Atlet Atletik NTB \\
\hline - & Anggun Yolanda & Atlet Panjat Tebing NTB \\
\hline - & Arum Hida & Atlet Taekwondo NTB \\
\hline
\end{tabular}

\subsection{Pengumpulan Data}

Metode dokumentasi, observasi dan wawancara menjadi metode utama pengumpulan data, seperti yang direkomendasikan oleh Jennings (2011). Penelitian ini menggunakan dua jenis data yaitu data primer dan data sekunder. Data primer dikumpulkan menggunakan sejak tanggal 10 Agustus sampai 31 agustus 2020. Alat yang digunakan dalam proses pengumpulan data adalah smartphone, recorder, instrumen guiding question agar proses penggalian lebih terarah dan alat tulis untuk membuat catatan-catatan dalam proses penelitian.

Proses dokumentasi dilakukan dengan mengumpulkan dokumen-dokumen terkait aturan berpakaian pada event bola voli pasir yang diungkapkan secara online melalui media sosial dan pengambilan foto di tempat pemusatan latihan. Observasi dilakukan dengan mengunjungi tempat pemusatan latihan voli pasir dan sekertariat PBVSI. Selanjutnya, metode pengumpulan data utama pada penelitian ini adalah wawancara. Proses wawancara dilaksanakan melalui dua metode yaitu wawancara langsung dengan beberapa informan yang berasal dari NTB dan wawancara daring menggunakan aplikasi whatsapp dengan informan yang berasal dari luar NTB. Pemilihan metode wawancara disesuaikan dengan kenyamanan informan mengingat keadaan pandemi COVID-19 yang tidak memungkinkan bertemu langsung dengan informan. Wawancara secara satu per satu dilakukan dengan tujuan mendapatkan eksplorasi mendalam tentang pemikiran, perasaan, dan pemahaman mereka. Durasi wawancara berkisar antara 120-150 menit.

\subsection{Analisis Data}

Penelitian ini menggunakan open coding dan axial coding dalam proses analisinya. Open coding dirancang untuk mengekspresikan data dalam bentuk kode awal. Sebuah teks dapat diberi kode baris demi baris, kalimat demi kalimat, atau paragraf demi paragraf, atau kode dapat dihubungkan ke seluruh teks. Axial coding mengikuti open coding sebagai langkah selanjutnya untuk menyempurnakan dan membedakan kategori yang dihasilkan dari open coding. Dari sekian banyak kategori yang bermula dari open coding, dipilihlah yang tampaknya paling menjanjikan untuk dielaborasi lebih lanjut (Klenke, 2008). Untuk lebih spesifik dengan pengkodean, peneliti mengikuti proses yang disarankan oleh Löfgren (2013) dalam Valdivia (2018), yang mempertimbangkan langkah-langkah berikut: (1) Transkrip wawancara: semua transkrip dibaca dan catatan dibuat pada kesan pertama. (2) Pengkodean: kata-kata, frasa, dan kalimat penting diberi label untuk memulai proses pengkodean. Pengkodean didasarkan pada pernyataan yang berulang-ulang, fakta-fakta yang mengejutkan peneliti atau fakta-fakta yang secara eksplisit dinyatakan penting oleh peserta. (3) Kategorisasi: peneliti memutuskan kode mana yang paling penting, dan membuat kategori atau tema dengan menyatukan beberapa kode. (4) Konseptualisasi data: peneliti menganalisis kategori mana yang paling relevan dan bagaimana mereka terhubung satu sama lain. (5) Hasil: Kategori dan keterkaitannya merupakan hasil utama dari penelitian ini.

\subsection{Triangulasi Data}


Triangulasi merupakan teknik pemeriksaan keabsahan data yang memanfaatkan sesuatu yang lain. Menurut Moleong (2011), uji keabsahan data dalam penelitian kualitatif yang digunakan untuk mencapai standar memiliki empat kriteria yakni sebagai berikut:

- Kepercayaan (credibility): Pemenuhan kriteria ini dilakukan dengan pengecekan kesesuaian antara hasil pengamatan dan realitas di lapangan melalui proses konfirmasi oleh stakeholder. Pada proses observasi langsung di lokasi usaha sosial, beberapa stakeholder yang terlibat dalam usaha sosial bisa ditemui dan bersedia memberikan beberapa konfirmasi terkait fakta di lapangan.

- Keteralihan (transferability): Untuk membangun keteralihan, penulisan laporan hasil penelitian dilakukan seteliti dan secermat mungkin terkait fokus penelitian. Laporan hasil penelitian ini ditulis dengan secara rinci, jelas, sistematis dan dapat dipercaya sehingga hasil penelitian ini mudah dipahami dan diterapkan oleh pembaca.

- Kebergantungan (dependability): Untuk menghindari kesalahan dalam memformulasikan hasil penelitian, dilakukan konsultasi dengan berbagai pihak untuk ikut memeriksa proses penelitian yang dilakukan peneliti, agar temuan peneliti dapat dipertahankan dan dapat dipertanggungjawabkan secara ilmiah. Pihak yang ikut memeriksa adalah dosen pembimbing pada penelitian ini.

- Kepastian (confirmability): Kriteria ini ikut diperiksa oleh dosen pembimbing penelitian ini, sama seperti pada kriteria sebelumnya. Konfirmabilitas dalam penelitian dilakukan bersamaan dengan dependabilitas. Perbedaannya terletak pada orientasi penilaian. Konfirmabilitas digunakan untuk menilai hasil penelitian. Sedangkan dependabilitas digunakan untuk menilai proses penelitian, mulai mengumpulkan data sampai pada bentuk laporan yang terstruktur dengan baik.

\section{HASIL PENELITIAN DAN PEMBAHASAN}

Tujuan dari analisis ini adalah untuk mengidentifikasi persepsi atlet wanita muslim terhadap aturan berpakaian pada event bola voli pasir di Indonesia. Dalam analisis, data diinterpretasikan dengan memberikan kode berupa kata-kata tertentu menunjukkan topik yang muncul dan membentuk tema. Tema yang muncul akan dicatat dan dihitung frekuensinya. Selanjutnya dilakukan pengelompokkan tema menjadi sebuah kategori berdasarkan kesamaan dan relevansi fokus dan konteks penelitian untuk membentuk suatu konsep tertentu (Saufi, et al., 2014). Kategori mungkin didefinisikan berdasarkan pertanyaan penelitian dan/atau teori dan konstruksi yang mendasari. Temuan dalam penelitian ini terdiri dari 3 kategori yang muncul dari 13 tema yang muncul dari informan seperti pada Tabel 2

Tabel 2 Contoh Frekuensi Tema Yang Muncul

\begin{tabular}{|l|l|c|}
\hline \multicolumn{1}{|c|}{ Ketegori } & \multicolumn{1}{|c|}{ Tema } & Frekuensi \\
\hline \multirow{4}{*}{$\begin{array}{l}\text { Orientasi Otentisitas } \\
\text { dan Profesionalisme }\end{array}$} & Karakteristik event voli pasir & 23 \\
\cline { 2 - 3 } & Budaya Negara Asal Voli Pasir & 21 \\
\cline { 2 - 3 } & Taat Aturan Internasional & 17 \\
\cline { 2 - 3 } & Kenyamanan dan Keluwesan & 15 \\
\cline { 2 - 3 } & Menjaga kekompakan dan profesionalisme & 25 \\
\hline \multirow{4}{*}{$\begin{array}{l}\text { Orientasi Moderat } \\
\text { dan Prestasi Atlet }\end{array}$} & Dukungan Lingkungan & 10 \\
\cline { 2 - 3 } & Minat Atlet & 15 \\
\cline { 2 - 3 } & Performa atlet; keluwesan dan optimalisasi gerak & 22 \\
\cline { 2 - 3 } & Perkembangan Voli Pasir nasional & 13 \\
\hline Orientasi nilai agama & Norma Agama dan Budaya, & 12 \\
\cline { 2 - 3 } dan budaya & Menutup Aurat Wanita & \\
\hline
\end{tabular}

jmm.unram.ac.id 


\begin{tabular}{|l|l|c|}
\hline & Kesetaraan budaya dunia & 15 \\
\cline { 2 - 3 } & Identitas agama dan budaya diatas prestasi olahraga & 8 \\
\hline
\end{tabular}

Analisis konten merupakan analisis yang sangat mendalam karena setiap kata, kalimat hingga paragraf diinterpretasikan dengan sangat teliti. Makna-makna eksplisit yang disebutkan oleh informan dapat dengan mudah diketahui melalui metode analisis konten. Maka dari itu, persepsti atlet wanita Muslim terhadap aturan berpakaian pada event bola voli pasir di Indonesia dapat dijelaskan secara detail dan sistematis. Hasil dari analisis ini juga didapat langsung dari data tanpa perlu memaksakan praduga perspektif teoritis seperti yang disebutkan oleh Moldavska \& Welo (2017).

Namun proses analisis konten pada penelitian ini terkandala oleh sedikitnya pengetahuan penelitian sehingga membutuhkan waktu yang sangat lama untuk akhirnya mendapatkan hasil analisis. Tahapan tersulit pada analisis konten adalah mengelompokkan kode yang sangat banyak ke dalam kategori yang sesuai. Saat berada pada keadaan tersebut, mempelajari dan memahami teori-teori dalam penelitian dengan lebih mendalam dan lebih banyak mencari referensi adalah hal yang dilakukan peneliti untuk mengatasi masalah yang ada saat proses analisis data. Selain itu, analisis konten mengharuskan untuk fokus pada pertanyaan penelitian dan teori yang digunakan sehingga proses analisis tidak melebar dan keluar dari fokus penelitian. Kuckartz (2014) menjelaskan bahwa pada analisis konten, semakin banyak berorientasi pada teori, semakin luas pengetahuan peneliti, semakin fokus pertanyaan penelitian, dan semakin spesifik hipotesis yang ada, maka semakin mudah untuk berpindah dari kode ke kategori.

\section{KESIMPULAN}

Penelitian ini menganalisis persepsi atlet wanita muslim terhadap aturan berpakaian pada event bola voli pasir di Indonesia dengan menggunakan metode analisis. Hasil dari penelitian ini dapat disimpulkan bahwa penggunaan analisis konten deduktif sebagai metode penelitian adalah untuk menguji ulang data yang ada dalam konteks baru, menguji kategori, konsep, model, atau hipotesis didasarkan pada pekerjaan sebelumnya seperti teori, model, peta pikiran, dan tinjauan literatur sehingga memberikan wawasan baru dan meningkatkan pemahaman tentang persepsi atlet wanita muslim terhadap aturan berpakaian pada event bola voli pasir di Indonesia, sehingga didapatkan deskripsi fenomena yang lebih luas dan lebih ringkas, serta untuk mendeskripsikan dan mengukur hasil penelitian tersebut. Hasil Analisis konten yang dilakukan pada artikel ini yaitu dengan melakukan pengkodean, mengelompokkan kode-kode menjadi tema/subtema dan kategori. Tema dan kategori dihasilkan dari analisis open dan axial koding. Analisis konten yang dilakukan pada artiker ini menghasilkan 3 kategori, 13 tema dan 205 topik yang saling berhubungan untuk menjawab pertanyaan penelitian.

\section{Implikasi Teoritis}

Hasil penelitian ini memperkuat beberapa teori yaitu penelitian ini mengembangkan beberapa hasil penelitian sebelumnya. Penelitian mengkonfirmasi hasil penelitian Bengsston (2016). Temuan dalam penelitian ini adalah data penelitian kualitatif dapat diperoleh dari wawancara, observasi, foto dan dokumentasi. Salah satu metode dalam analisisnya adalah analisis konten. Proses melakukan analisis konten terdiri dari decontextualization, Recontextualization, categorization dan compilation. Untuk menemukan hasil maka perlu dilakukan tahapan - tahapan diatas untuk mendapatkan temasub-tema dan kategori. 
Penelitian ini juga mengkonfirmsai penelitian Downe-Wombolt (1992) yang mengemukakan bahwa dalam analisis konten memiliki kelebihan dalam menjaga kehilangan banyak informasi dari data asli. Analisis konten mampu megurangi dana penelitian katena analisis konten bisa dilakukan oleh satu peneliti. Namun kekurangan dalam analisis konten adalah waktu. Dengan cara mengkoding data untuk mendapatlan hasil, ini memakan waktu yang banyak untuk melakukan koding.

\section{Keterbatasan dan Saran Penelitian yang Akan Datang}

Artikel ini menjelaskan bagaimana menemukan persepsi aturan berpakaian pada event bola voli pasir di Indonesia melalui konten analisis. Metode analisis ini dapat digunakan pada fokus penelitian yang lebih luas lagi untuk menggali lebih dalam tentang teori maupun implementasi dalam studi kewirausahaan dan kepariwisataan. Selain itu, hasil penelitian ini menghasilkan banyak variabel-variabel untuk dilanjutkan dalam penelitian lanjutan dan menguji hubungan antar variabelnya.

\section{Acknowledgments}

Penelitian ini ditulis sebagai hasil dari kerjasama antara Kementrian Pemuda dan Olahraga Republik Indonesia dan Universitas Mataram.

\section{DAFTAR PUSTAKA}

Afrilian, P. (2018). Pengaruh Kesuksesan Penyelenggaraan Event Sport Tourism Triathlon Pariaman Dalam Meningkatkan Kunjungan Wisatawan Mancanegara Dari Tahun 2014 Sampai Tahun 2017. Jurnal Stamina, 1(1), 12-23.

Ahmad, N. (2017),“Toward advancing debates on Islamicmarketing: a renewed perspective", Journal of IslamicMarketing, Vol. 9 No. 1.

Alam, S., Mohd, R. and Hisham, B. (2011), "Is religiosity animportant determinant on Muslim consumer behaviour inMalaysia?", Journal of Islamic Marketing, Vol. 2 No. 1,pp. 8396.

Amara, M. (2008). An introduction to the study of sport in the Muslim world. In B. Houlihan (Ed.), Sport and society: A student Introduction (pp. 532-553). London, England: Sage.

Ariastini, N. N., Widhiarini, N. M. A. N., \& Oktaviani, P. E. (2018). Strategi pengembangan Mepantigan sebagai atraksi wisata budaya dalam mendukung sport tourism di Bali.

Battour, Hakimian, Ismail, dan Bogan, 2018; Battour, M. 2018. Muslim Travel Behavior in Halal Tourism. Mobilities, Tourism and Travel Behavior - Contexts and Boundaries. http://dx.doi.org/10.5772/intechopen.70370

Bengtsson, M. (2016). How to plan and perform a qualitative study using content analysis. NursingPlus Open, 2, 8-14

Burns, N., \& Grove, S.K. (2005). The Practice of Nursing Research: Conduct, Critique E Utilization. Elsevier Saunders, St Louis.

Downe-Wamboldt, B. (1992). Content analysis: method, applications, and issues. Health care for women international, 13(3), 313-321.

E. Rivani, 2018, Potensi Asian Games 2018 Bagi Perekonomian Indonesia, Info Singkat Bidang Ekonomi dan Kebijakan Publik, Kajian Singkat Terhadap Isu Aktual dan Strategis, Pusat Penelitian Badan Keahlian DPR RI X(10)/II: 19-24

El Fikri, M. (2019). Kajian Destinasi Wisata Halal Kota Medan Dalam Persepsi Pemasaran Wisata. JUMANT, 11(1), 263-270. 
Elo, S., Kääriäinen, M., Kanste, O., Pölkki, T., Utriainen, K., \& Kyngäs, H. (2014). Qualitative content analysis: A focus on trustworthiness. SAGE open, 4(1), 2158244014522633.

Erickson, K. (2017). Understanding Minnesota Muslim Girls' Experiences with Current Sports Uniforms and Their Preferences for the Design of Culturally Sensitive Sports UniformsFederation Internationale de Volleyball. (2019). 7, 22-43. Beach Volleyball. from http:/ / www.fivb.org/

Eriyanto. 2011. Analisis Isi : Pengantar Metodologi untuk Penelitian Ilmu Komunikasi dan Ilmu-ilmu Sosial Lainnya. Jakarta: Kencana Prenada Media Group.

Esposito, J. L., \& Mogahed, D. (2007). Battle for Muslims' hearts and minds: The road not (yet) taken. Middle East Policy, 14(1), 27-41

Gibson, H. J. (1998). Active sport tourism: who participates?. Leisure studies, 17(2), 155-170.

Gibson, H. J. 1998. Sport tourism: a critical analysis of research. Sport Management Review, 1(1): $45-76$.

Hamzeh,M.and Oliver,K.(2012),“Because I am MuslimI cannot wear a swimsuit', Muslim girls negotiateparticipation opportunities for physical activity",Research Quarterly for Exercise and Sport, Vol.83No.2

Hsieh, H. F., \& Shannon, S. E. (2005). Three approaches to qualitative content analysis. Qualitative health research, 15(9), 1277-1288.

Jennings, G. (2011). Tourism Research (Vol. Second Edition). Australia: Wiley Australia Tourism Series.

Khan, Jamil, Kareem, dan Imran, (2012). Khan, M. Y., Jamil, A., Khan, U. A., Kareem, U., dan Imran, G. (2012). Female Students Opinion about Women's Participation in Sports. International Journal of Academic Research in Business and Social Sciences, 2(9), 275.

Kinicki Angelo. Roberr Kreitner, 2003. Organizational Behavior Key Concepts, Skills dan Best Practtces $\backslash 1 \mathrm{c}$. Grau Hill Boston

Klenke, K. (Ed.). (2008). Qualitative research in the study of leadership. Emerald group publishing.

Kondracki, N. L., Wellman, N. S., \& Amundson, D. R. (2002). Content analysis: Review of methods and their applications in nutrition education. Journal of nutrition education and behavior, 34(4), 224-230.

Krippendorff, K. (2012). Content analysis: An introduction to its methodology. Sage publications. Kuckartz, U. (2014). Qualitative text analysis: A guide to methods, practice and using software. Sage.

Kusumaningrum, D., \& Fandeli, I. C. (2009). Persepsi Wisatawan Nusantara Terhadap Daya Tarik Wisata Di Kota Palembang (Doctoral dissertation, [Yogyakarta]: Universitas Gadjah Mada)

Lubis, Satrianingsih, dan Irmansyah, 2017; Lubis, m. R., satrianingsih, b., dan irmansyah, j. (2017). Evaluasi program pembinaan prestasi cabang olahraga bola voli pantai di ntb. Jurnal ilmiah mandala education.

Moldavska, A., \& Welo, T. (2017). The concept of sustainable manufacturing and its definitions: A content-analysis based literature review. Journal of Cleaner Production, 166, 744-755.

Moleong, Lexy J. (2011). Metode Penelitian Kualitatif, Edisi Revisi. Bandung: PT. Remaja Rosdakarya.

Moretti, F., van Vliet, L., Bensing, J., Deledda, G., Mazzi, M., Rimondini, M. \& Fletcher, I. (2011). A standardized approach to qualitative content analysis of focus group discussions from different countries. Patient education and counseling, 82(3), 420-428. 
Pattison, J. A. (2013). Female collegiate volleyball athletes' perceptions of identity, specific to sport and gender, as understood by their in-sport and everyday dress and appearance practices.

Pelana, R. (2013). Persepsi Atlet Terhadap Sdm Pplm Tentang Prestasi Atlet. Gladi: Jurnal Ilmu Keolahragaan, 7(2), 765-779.

Purnamasari, A. M. (2011). Pengembangan masyarakat untuk pariwisata di kampung wisata Toddabojo Provinsi Sulawesi Selatan. Journal of Regional and City Planning, 22(1), 4964.

Saufi, A., O'Brien, D., and Wilkins, H. 2014. Inhibitors to host commu nity participation in sustainable tourism development in developing countries. Journal of Sustainable Tourism, 22:5, 801-820, DOI : 10.1080/09669582.2013.861468

Steinfeldt, J. A., Zakrajsek, R. A., Bodey, K. J., Middendorf, K. G., \& Martin, S. B. (2013). Role of uniforms in the body image of female college volleyball players. The Counseling Psychologist, 41(5), 791-819.

Thoha, M. (2014). Perilaku Organisasi: Konsep Dasar dan Aplikasinya, cetakan ke-23. Jakarta: Rajawali Pers

Utomo, A. W. (2018). Perkembangan Industri Olahraga Obyek Wisata dan Rekreasi di Kabupaten Magetan. In Prosiding Seminar Nasional Ilmu Keolahragaan UNIPMA, 1 (1), h.116-126

Valdivia, Carmen Paola Sota. (2018). The Role of Social Entrepreneurs in Community-Based Rural Tourism in Developing Countries. Graduate Thesis, University of Ljubljana.

Waljee, A. (2008) Researching transitions: gendered education, marketisation and Islam in Tajikistan. In S. Fennell, dan M. Arnot (Eds) Gender Education and Equality in a Global Context, London Routledge.

Weaving, C. (2012). Buns of Gold, Silver, and Bronze. The Olympics and philosophy, 228-241.

Wilson, J. A., \& Liu, J. (2011). The challenges of Islamic branding: navigating emotions and halal. Journal of Islamic marketing.

Wirdati, M. R. (2006). Muslim Women and Sports in the Malay World: The Crossroads of Modernity and Faith. Chiang Mai: Silkworm books. 